\title{
Application of Computational Fluid Dynamic Simulation to SiC CVD Reactor for Mass Production
}

\author{
Jin-Won Seo and Kyoon $\mathrm{Choi}^{\dagger}$ \\ KICET Icheon Branch, Korea Institute of Ceramic Engineering and Technology, Icheon 467-843, Korea \\ (Received October 25, 2013; Revised October 30, 2013; Accepted October 31, 2013)

\section{대량 생산용 $\mathrm{SiC} \mathrm{CVD}$ 리엑터에의 전산유체역학 시뮬레이션의 적용 \\ 서진원 · 최 균 ${ }^{\dagger}$ \\ 한국세라믹기술원 이천분원 \\ (2013년 10월 25일 접수 ; 2013년 10월 30일 수정 ; 2013년 10월 31일 채택)}

\begin{abstract}
Silicon carbide ( $\mathrm{SiC}$ ) materials are typical ceramic materials with a wide range of uses due to their high hardness and strength and oxidation resistance. In particular, due to the corrosion resistance of the material against acids and bases including the chemical resistance against ionic gases such as plasma, the application of $\mathrm{SiC}$ has been expanded to extreme environments. In the $\mathrm{SiC}$ deposition process, where chemical vapor deposition (CVD) technology is used, the reactions between the raw gases containing $\mathrm{Si}$ and $\mathrm{C}$ sources occur from gas phase to solid phases; thus, the merit of the CVD technology is that it can provide high purity SiC in relatively low temperatures in comparison with other fabrication methods. However, the product yield rarely reaches $50 \%$ due to the difficulty in performing uniform and dense deposition. In this study, using a computational fluid dynamics (CFD) simulation, the gas velocity inside the reactor and the concentration change in the gas phase during the SiC CVD manufacturing process are calculated with respect to the gas velocity and rotational speed of the stage where the deposition articles are located.
\end{abstract}

Key words: Ilicon carbide, Chemical vapor deposition, CFD simulation, Chemical reaction, RBSiC

\section{1. 서 론}

탄화규소는 전형적인 구조 재료로 강도와 경도가 뛰어 나고 화학적으로 안정하며 내열 특성이 뛰어나서 극한 환 경인 항공/우주용 세라믹스나 내플라즈마/내화학 특성을 요하는 반도체 공정용 세라믹스로서 그 가치가 높다. 특 히, 탄화물로는 특이하게 대기 중에서도 상당 시간 동안 견딜 수 있는 내산화 특성까지 갖추고 있어서 점점 그 활 용 범위가 넓어지고 있다. ${ }^{1,2)}$

탄화규소는 일반적으로 탄소 프리폼을 고온에서 액화 된 실리콘과 접촉 반응시켜서 제조하게 되는데 이렇게 제 조된 탄화규소를 반응소결 탄화규소(reaction-bonded silicon carbide: $\mathrm{RBSiC}$ )라고 하며 비교적 복잡한 형상의 성형체 를 큰 체적 변화 없이 제조할 수 있으므로 가공 비용이 적게 들어서 상당히 폭 넓게 활용되고 있다 ${ }^{2)}$. 그러나 공 정의 특성상, 항상 미반응의 실리콘과 탄소가 내부에 남

\footnotetext{
${ }^{\dagger}$ Corresponding author : Kyoon Choi

E-mail : knchoi@kicet.re.kr

Tel : +82-31-645-1456 Fax : +82-31-645-1493
}

게 되므로 이로 인하여 물성의 저하를 가져올 수 있고 사 용 중에 내부에 기포가 형성될 수 있다. 이러한 문제들은 비교적 간단한 방법으로 극복될 수 있는데 $\mathrm{RBSiC}$ 위에 두꺼운 탄화규소 층을 화학기상 증착법(CVD)으로 입혀 주는 방법이다. 이렇게 형성된 $\mathrm{CVD}$ 탄화규소 층은 치밀 할 뿐만 아니라 고순도이고 잔류 탄소의 농도도 낮아서 전체 $\mathrm{RBSiC}$ 위에 고르게 증착시킬 경우에 내부의 잔류 상이 밖으로 나오는 것을 억제할 수 있다. 이런 방법은 특히 반도체 에칭 공정과 같이 파티클의 생성이 제품 생 산에 큰 영향을 미칠 수 있는 공정에 효과적으로 대응할 수 있는 기술이다. ${ }^{1,2)}$

탄화규소를 $\mathrm{CVD}$ 로 증착하는 방법은 MTS(methyltrichlorosilane: $\mathrm{CH}_{3} \mathrm{SiCl}_{3}$ )와 같이 규소와 탄소의 비가 $1: 1$ 인 액상의 원료에 수소를 버블링하여 열분해하는 방법으로 간단하게 제조할 수 있으나-6) 열분해 시에 가스 투입구 근처에서 반응이 빠르게 일어나기 때문에 전체 반응기에 걸쳐서 균일하게 반응이 일어나도록 조절하기가 어렵다. 더구나 대량 생산용 반응기의 경우에 직경이 1 미터 이 상이고 높이도 1.5 미터가 넘는 경우가 대부분이라서 샘 플의 위치에 따라서 두께 편차가 심하게 나타나는 등 생 
산품의 수율을 올리는 문제가 주요한 이슈가 되고 있다. ${ }^{7)}$

최근에 Kim등은 전산유체역학(computational fluid dynamics: CFD) 모사를 통하여 리엑터 내부의 유속이나 조성 의 분포를 예측하는 기술을 통하여 $\mathrm{CVD}$ 리엑터 내부의 현상을 이해할 수 있음을 제안하였다,8). 최근까지 탄화 실리콘의 $\mathrm{CVD}$ 공정을 $\mathrm{CFD}$ 를 통하여 예측한 모델은 수 차례 제시되었으나 ${ }^{15,9-12)}$ 대부분의 연구가 단결정 탄화규 소 증착과 관련된 시뮬레이션이고 대면적의 다결정 후막 에 응용하고자 하는 연구 $5,9,11$ 는 충분하지 못하였다. 본 연구에서는 양산용 시스템에 대하여 CFD 해석을 통하여 탄화규소 막의 증착 균일도를 향상시키기 위한 서셉터의 구조와 공정 조건에 대한 연구를 수행하였다.

\section{2. 실험방법}

\subsection{CVD 반응기}

해석에 적용되는 $\mathrm{CVD}$ 반응기는 앞선 논문에서 제시한 바와 같이 내부 증착 영역의 직경이 $950 \mathrm{~mm}$ 정도 되는 양산용 CVD 장치로 챔버 내부에 증착용 스테이지가 회 전되는 구조를 갖고 있다. 계산 시간의 단축을 위하여 실 제 반응기의 가스 주입구의 직경을 제외하고 $1: 3$ 의 축적 비로 축소한 유동 공간 만을 3차원으로 나타내면 Fig. 1(a) 와 같다. 스테이지는 등방성 탄소로 구성되어 있으며 스 테이지 위에 다시 3 단으로 기물을 올려놓을 수 있는 서 셉터를 올려 놓고 균일한 막의 형성을 위하여 회전시키 는 구조이다(Fig. 1(b)). 가스 주입구는 총 3 개로 구성되어 있으며 주입구를 통해 들어온 가스는 서셉터 영역을 지 나 출구로 빠져나가는 수평 흐름 구조를 가지고 있다.

\subsection{CFD 해석}

$\mathrm{CFD}$ 프로그램으로는 상용 소프트웨어인 $\mathrm{COMSOL}$ multiphysics $4.3 \mathrm{~b}$ 를 사용하였으며, CFD 모듈과 화학반응 모듈을 coupling하여 열 - 유동 해석과 화학반응에 대한 시뮬레이션을 수행하였다.

CFD 해석을 위한 지배방정식으로 Navier-Stokes 방정식 ${ }^{13)}$ 을 사용하였다. 반응기 내부의 온도와 압력은 각각 $1300^{\circ} \mathrm{C}$, 100 torr로 설정하였으며 moving wall 조건으로 스테이지 회전속도(stage rotation speed: SRS)를 1, 3, 6으로 변경하 면서 내부의 유동을 해석하였다. 또한 상중하 세 곳의 가 스 주입구 중 상부와 하부의 주입구를 통해 각각 알곤과 수소 가스를 $1: 1$ 의 몰비로 주입하였는데 이 때 유속에 따른 농도 분포를 알아보기 위해 유속을 $0.3,0.6,1.2 \mathrm{~m} / \mathrm{s}$ 로 변화시키면서 유속의 변화를 관찰하였다. 이 때, 다성 분계의 확산에 대한 지배방정식은 Maxwell-Stefan 확산식 ${ }^{14)}$ 을 적용하였다. 여기서 알곤과 수소를 실제 $\mathrm{CVD}$ 공정의 모델 가스로 사용한 이유는 CVD 공정에서 발생하는 가 스의 $99 \%$ 이상이 수소와 염화수소인데 염화수소와 알곤

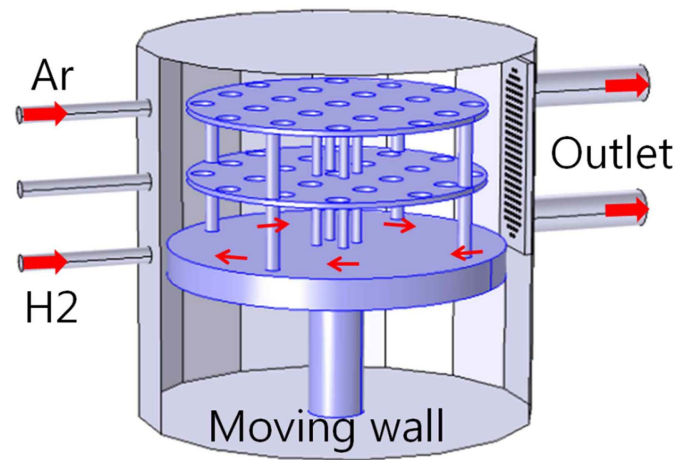

(a)

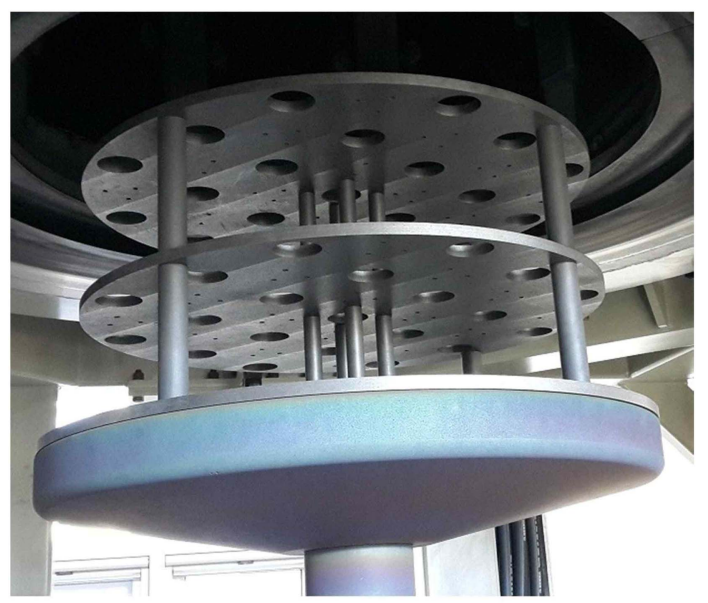

(b)

Fig. 1. (a) 3-dimensional description of fluid and moving wall region and (b) the photograph of susceptor and stage.

의 분자량이 각각 36.5 와 40 으로 유사하여 수소와 알곤의 혼합 양상을 관찰하면 유체 거동의 개략적인 양상을 확 인할 수 있기 때문이다.

사용자 조정 격자를 사용하여 약 210 만개의 사면체(tetrahedral) 격자를 생성하여 minimum element quality를 0.1 내외가 되도록 하였다. 정상 상태(steady state)에서의 결 과를 PARDISO solver를 사용하여 도출하였고 pivoting perturbation은 $10^{-8}$ 으로 설정하였다. 해석에 사용된 워크 스테이션은 DELL사의 PRECISION T7500(Intel(R) Xeon(R) CPU G2.67GHz, RAM $192 \mathrm{~GB}$ )이었으며 스테이지 회전속 도와 유속에 따라 최대 6시간 정도의 시간이 소요되었다.

\section{3. 결과 및 고찰}

\section{1. 스테이지 회전 속도(SRS)에 따른 가스 분포}

Fig. 2는 알곤과 수소 가스가 각각 위 아래 주입구를 통 하여 $0.3 \mathrm{~m} / \mathrm{s}$ 의 속도로 흘러 들어가고, 스테이지의 회전 속도가 1, 3, 6 RPM 일 때 리엑터 내부의 수소 몰분율을 


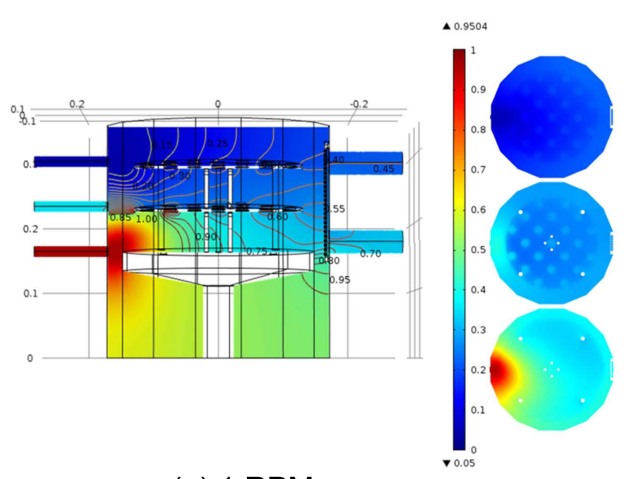

(a) 1 RPM

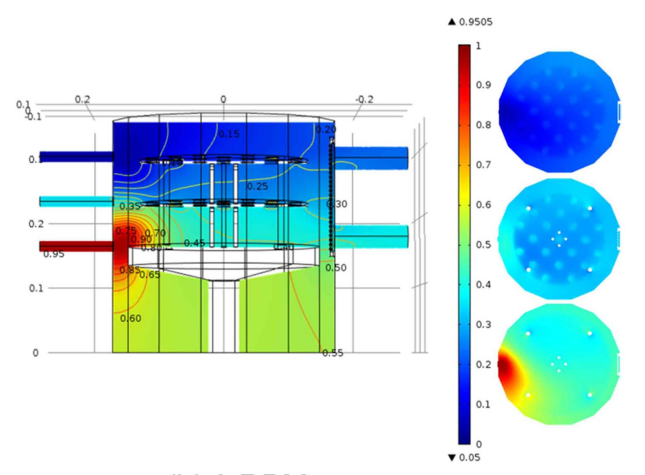

(b) 3 RPM

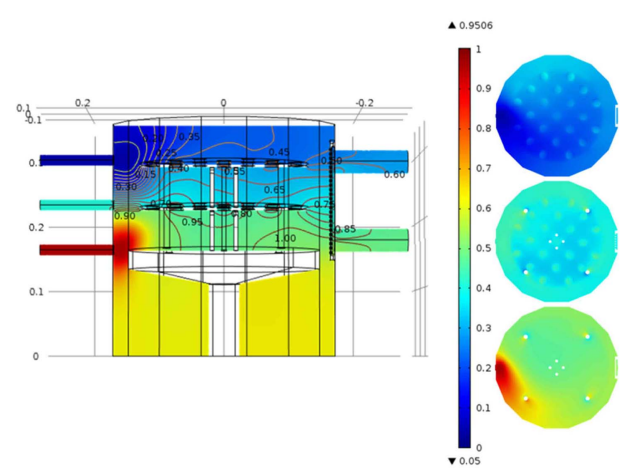

(c) 6 RPM

Fig. 2. Spatial distribution of hydrogen molar fraction with stage rotation speed (SRS) of (a) 1 RPM, (b) 3 RPM, and (c) 6 RPM at $0.3 \mathrm{~m} / \mathrm{s}$ of gas inflow speed.

Table 1. Average $(\bar{y})$ and Standard Deviation $(\sigma)$ of Ar Molar Fraction $\left(\mathrm{F}_{\mathrm{Ar}}\right)$ at the Different Stages with Stage Rotation Speed (SRS)

\begin{tabular}{cccc}
\hline SRS $(\mathrm{RPM})$ & $\bar{y}(\sigma)$ of $\mathrm{F}_{\mathrm{Ar}}$ at top stage & $\bar{y}(\sigma)$ of $\mathrm{F}_{\mathrm{Ar}}$ at middle stage & $\bar{y}(\sigma)$ of $\mathrm{F}_{\text {Ar }}$ at bottom stage \\
\hline 1 & $0.3910(0.0864)$ & $0.1933(0.0265)$ & $0.1300(0.0367)$ \\
3 & $0.3943(0.0494)$ & $0.2176(0.0258)$ & $0.1462(0.0360)$ \\
6 & $0.4640(0.0299)$ & $0.3030(0.0184)$ & $0.1964(0.0362)$ \\
\hline
\end{tabular}

정상 상태에서 도식화 것이다. 왼 쪽은 입구와 출구를 포 함하는 $\mathrm{zx}$ 평면 상에서 수소의 몰분율을 나타낸 것으로 리엑터 내부의 전체적인 농도 분포를 알 수 있다. 오른 쪽의 둥근 단면은 삼 단의 스테이지 바로 윗부분에 있는 가스의 조성을 $\mathrm{xy}$ 평면 상에서 도식화한 것으로 스테이 지 위에서의 몰분율을 알 수 있는 그림이다. 전체적인 농 도 분포를 보면 SRS가 빨라질 수록 상단과 하단의 스테 이지에서 두 종류의 가스가 잘 섞여서 같은 스테이지 내 에서 균일도가 향상되는 양상을 확인할 수 있다. 또한 $\mathrm{SRS}$ 가 커질수록 강한 와류의 형성으로 위 쪽에서 투입된 알곤 가스가 아래 쪽 공간으로 확산되지 못하는 현상을 관찰할 수 있다. 이는 각 단에서의 와류의 형성으로 인하 여 가스의 농도가 영향을 받을 수 있다는 흥미로운 결과 로 판단된다.

좀 더 세부적인 결과를 살펴보기 위하여 반응기 중심 으로부터 일정 간격 떨어진 위치에서 알곤 가스의 몰분 율이 $\mathrm{z}$ 축을 따라서 스테이지 위에서 어떻게 변화하는가
를 Fig. 3에 나타내었다. 먼저 스테이지 위에서 농도를 선 택한 곳을 Fig. 3(d)에 위치 1에서 5까지 색깔 별로 도시 하였다. 각 위치에서 $\mathrm{z}$ 축을 따라서 스테이지가 있는 곳 을 제외하고 윗단과 중간단 그리고 하단에서의 알곤 농 도는 Fig. 3과 같이 스테이지의 RPM에 따라 상이하게 나 타난다. 스테이지 회전 속도가 1,3,6 RPM으로 변함에 따라 각 유동 공간 내에서의 알곤 가스의 몰분율을 각각 Fig. 3의 (a), (b), (c)로 나타내었다. 스테이지 별 평균 농 도에서는 $\mathrm{SRS}$ 가 상승할 수록, 전체적인 스테이지에서의 알곤의 몰분율이 커지는 경향을 확인할 수 있으며 이는 Table 1에서 평균 값의 상승으로도 확인할 수 있다. 이는 스테이지의 회전이 만드는 와류에 의하여 위쪽 투입구로 들어오는 알곤 가스가 아래 쪽으로 확산되지 못하기 때 문으로 여겨진다. 또한 스테이지의 SRS가 상승하면서 위 치 별로 농도의 차이가 줄어서 좀 더 균일한 농도 분포 를 보이는 것도 Table 1 의 표준 편차의 감소로 정량적으 로 확인할 수 있다. 


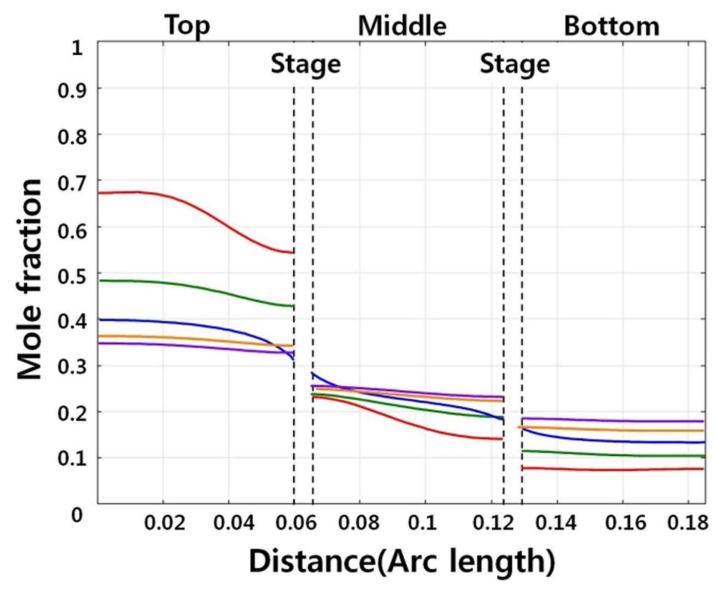

(a) 1 RPM

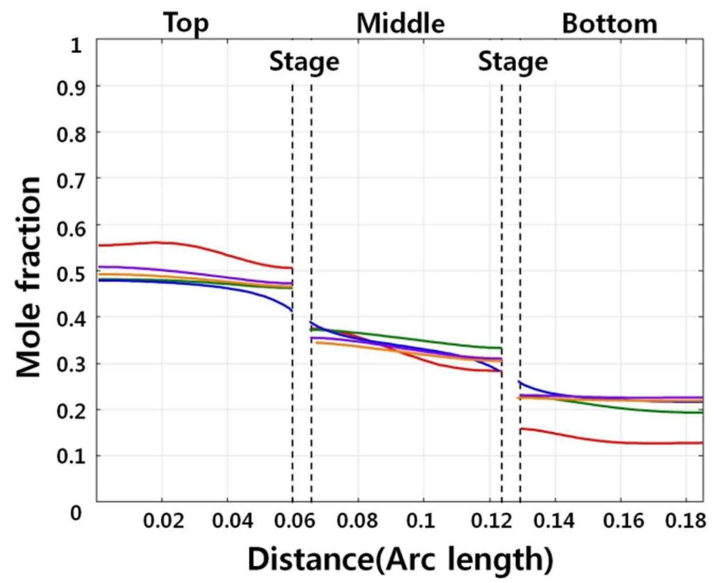

(c) 6 RPM

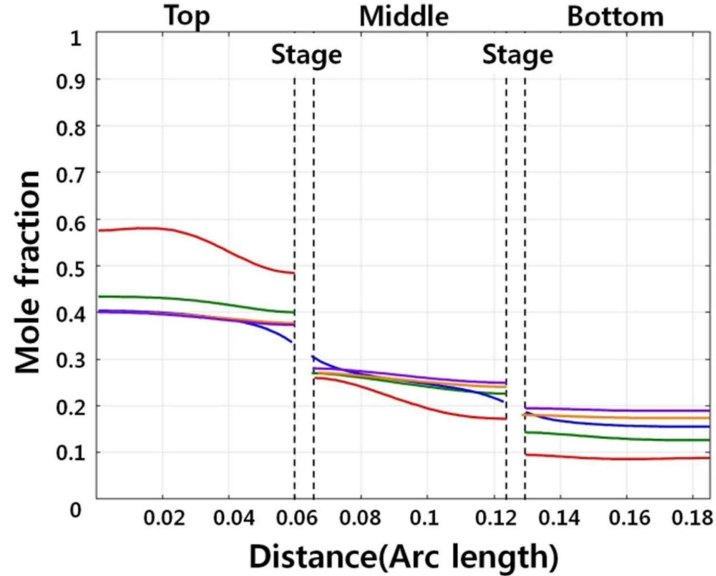

(b) 3 RPM

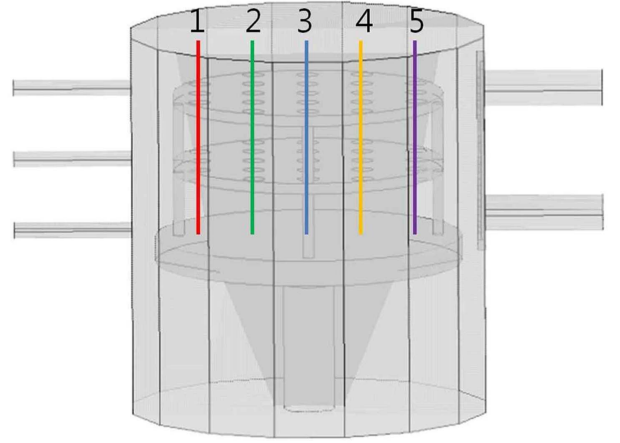

(d)

Fig. 3. Diagram of Ar mole fraction with stage rotation speed (SRS) of (a) 1 RPM, (b) 3 RPM, (c) 6 RPM along z-axis of 5 traces shown at (d) on the stage in reactor.

\section{2. 유속에 따른 가스 분포}

Fig. 4는 스테이지의 회전속도가 3 RPM으로 일정하고 알곤과 수소 가스가 각각 위 아래 주입구를 통하여 0.3 , $0.6,1.2 \mathrm{~m} / \mathrm{s}$ 의 속도로 흘러 들어갈 때 리엑터 내부의 알 곤 몰분율을 정상 상태에서 도식화 것이다. 왼 쪽은 입구 와 출구를 포함하는 $\mathrm{zx}$ 평면 상에서 수소의 몰분율을 나 타낸 것으로 리엑터 내부의 전체적인 농도 분포를 알 수 있다. 오른쪽의 둥근 단면은 삼 단의 스테이지 바로 윗부 분에 있는 가스의 조성을 $\mathrm{xy}$ 평면 상에서 도식화한 것으 로 스테이지 위에서의 몰분율을 알 수 있는 그림이다. 전 체적인 농도 분포를 보면 유속이 빨라질 수록 상단과 하 단의 스테이지에서 두 종류의 가스가 잘 섞이지 못한 채 로 출구로 흘러 나가는 현상이 관찰되며 이를 통하여 유 속이 빨라질수록 스테이지 간의 가스들이 잘 섞이지 못 하고 출구에 도달하는 현상을 확인할 수 있다.

좀 더 세부적인 결과를 알아보기 위하여 Fig. 5와 같이
반응기 중심으로부터 일정 간격 떨어진 위치에서 알곤 가 스의 몰분율을 $\mathrm{z}$ 축을 따라서 스테이지 위에서 나타내었 다. 먼저 Fig. 3(d)의 위치 1에서 5의 위치에서 유속이 각 각 $0.3,0.6,1.2 \mathrm{~m} / \mathrm{s}$ 로 변함에 따라 각 유동 공간 내 최 상단에서부터 하단 스테이지까지의 알곤 가스의 몰분율 을 Fig. 5의 (a), (b), (c)에 그래프로 나타내었다. Table 2 의 스테이지 별 평균 농도에서 유속이 $0.3 \mathrm{~m} / \mathrm{s}$ 일 때, 하단 스테이지에서 알곤 가스의 몰분율이 가장 높게 나타나는 것을 통해 유속이 느릴 수록 반응기 유동 공간 하부로 확산 이 용이한 것을 확인할 수 있다. 가스 주입 속도가 $0.3 \mathrm{~m} / \mathrm{s}$ 일 때 상단과 중간단 스테이지의 농도 표준편차가 $0.6 \mathrm{~m} / \mathrm{s}$, $1.2 \mathrm{~m} / \mathrm{s}$ 일 때보다 더 작은 값을 가지므로 유속이 $0.3 \mathrm{~m} / \mathrm{s}$ 일 경우, 농도 분포는 유속이 빠를 때보다 균일함을 확인 할 수 있다. Fig. 5(c)에서 볼 수 있듯이 하단 스테이지의 경우에는 속도가 빨라지면 표준편차가 더 작은 값을 가 져서 균일한 농도 분포를 보이지만 농도의 절대 값은 매 


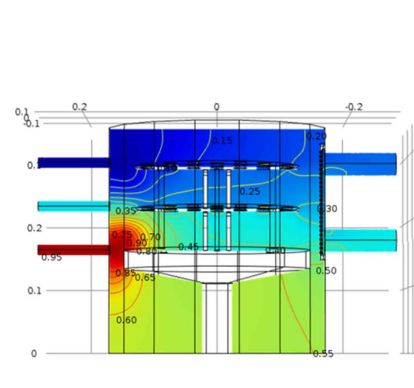

(a) $0.3 \mathrm{~m} / \mathrm{s}$
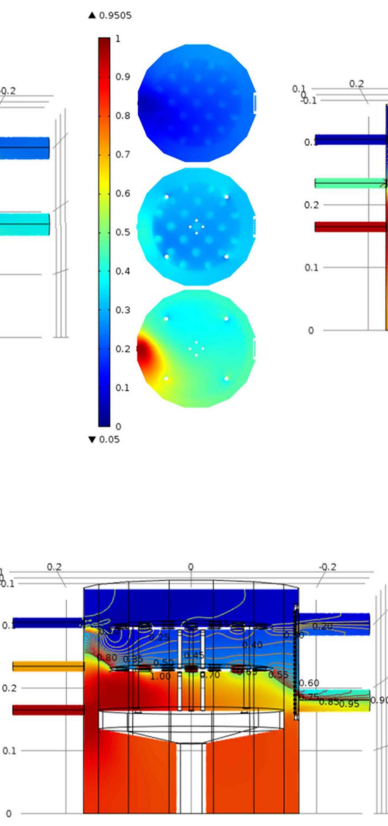

(b) $0.6 \mathrm{~m} / \mathrm{s}$

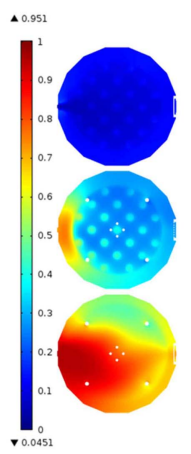

(c) $1.2 \mathrm{~m} / \mathrm{s}$

Fig. 4. Spatial distribution of hydrogen molar fraction with gas inflow velocity of (a) $0.3 \mathrm{~m} / \mathrm{s}$, (b) $0.6 \mathrm{~m} / \mathrm{s}$, and (c) $1.2 \mathrm{~m} / \mathrm{s}$ at $3 \mathrm{RPM}$ of stage rotation speed (SRS).

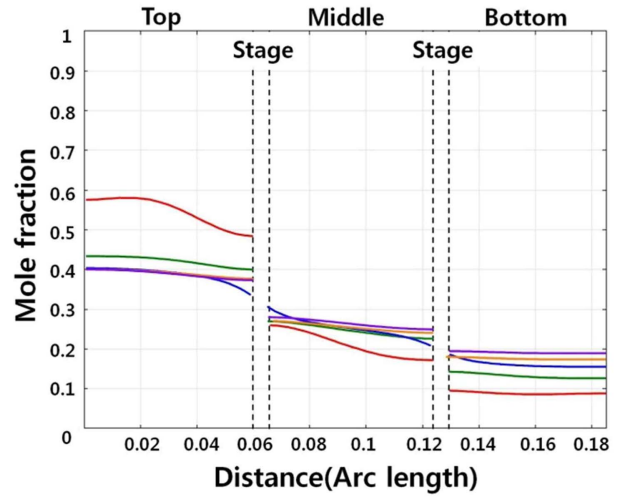

(a) $0.3 \mathrm{~m} / \mathrm{s}$

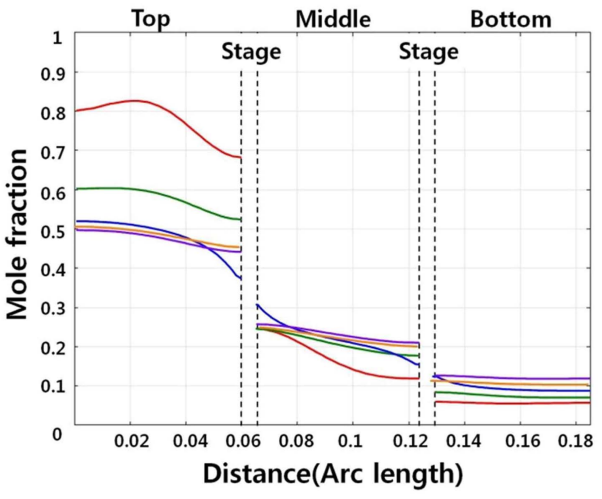

(b) $0.6 \mathrm{~m} / \mathrm{s}$

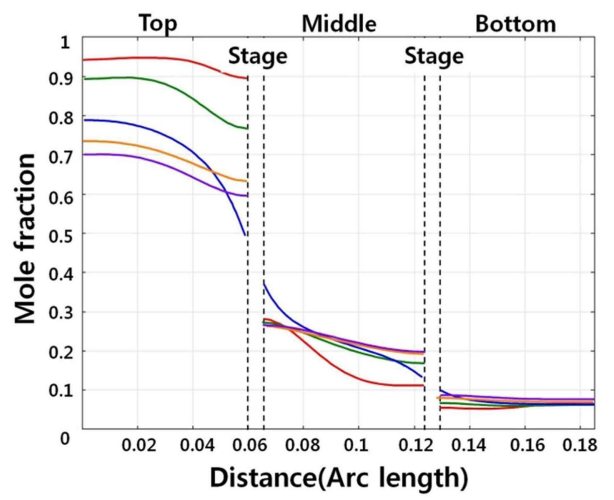

(c) $1.2 \mathrm{~m} / \mathrm{s}$

Fig. 5. Diagram of Ar molar fraction with gas inflow velocity of (a) $0.3 \mathrm{~m} / \mathrm{s}$, (b) $0.6 \mathrm{~m} / \mathrm{s}$, and (c) $1.2 \mathrm{~m} / \mathrm{s}$ along z-axis of 5 spots as shown in Fig. 3(d). 
Table 2. Average $(\bar{y})$ and Standard Deviation $(\sigma)$ of Ar Molar Fraction $\left(\mathrm{F}_{\mathrm{Ar}}\right)$ at the Different Stages with Gas Inflow Velocity (GIV)

\begin{tabular}{cccc}
\hline $\mathrm{GIV}(\mathrm{m} / \mathrm{s})$ & $\bar{y}(\sigma)$ of $\mathrm{F}_{\mathrm{Ar}}$ at top stage & $\bar{y}(\sigma)$ of $\mathrm{F}_{\text {Ar }}$ at middle stage & $\bar{y}(\sigma)$ of $\mathrm{F}_{\text {Ar }}$ at bottom stage \\
\hline 0.3 & $0.3943(0.0494)$ & $0.2176(0.0258)$ & $0.1462(0.0360)$ \\
0.6 & $0.4956(0.1057)$ & $0.1719(0.0329)$ & $0.0872(0.0221)$ \\
1.2 & $0.6776(0.1397)$ & $0.1605(0.0334)$ & $0.0680(0.0051)$ \\
\hline
\end{tabular}

우 낮아져서 알곤이 최하단 스테이지까지 내려오기 어렵 게 됨을 확인할 수 있었다.

\section{4. 결 론}

이 연구에서는 스테이지의 회전 속도와 가스의 주입 속 도가 가스의 농도 분포에 어떠한 영향을 미치는가를 전 산유체역학(CFD) 시뮬레이션을 통하여 확인하였다. 그 결 과, 스테이지의 회전수가 클 경우 스테이지 내에서 농도 의 편차는 줄어들지만 스테이지의 회전에 의하여 형성되 는 와류에 의하여 위 단에서 공급되는 가스가 아래 쪽으 로 유입되지 못하여 챔버 내에서의 농도의 차가 커지는 현상을 확인 할 수 있었다. 또한 유속이 빨라지는 경우에 도 빨라지는 유속에 의하여 위 쪽의 가스가 아래 쪽으로 확산되지 못하는 경향을 나타내었고 이에 따라 스테이지 간의 가스의 농도 차이가 커지는 양상을 관찰할 수 있었 다. 이러한 양상은 3 배로 큰 실제 양산용 크기의 CVD 리 엑터에서도 같을 것으로 예상되지만 유속과 알곤의 농도 등의 구체적인 값은 리엑터 크기에 따라서도 달라질 수 있으므로 실제 공정에 가까운 조건에서의 리엑터에 대한 시뮬레이션도 별도로 진행되어야 할 것이다.

\section{Acknowledgement}

이 논문은 지식경제부의 WPM 사업(사업번호: 10037913) 의 지원으로 이루어졌으며 이에 감사드립니다.

\section{REFERENCES}

1. K.-S. Cho, S.-H. Yoon, H. Chung, S.-H. Chae, K.-Y. Lim, Y.-W. Kim, and S.-H. Park, "SiC Materials Techniques for Semiconductor Production Line (in Korean)," Ceramist, 10 [6] 33-48 (2007).

2. J.-H. Lee, "Analysis on Development Process of Semiconductor Industry and Competitiveness of Semiconductor
Equipment Industry in Korea (in Korean)," pp. 6-8, Master Thesis, Gyonggi University, Suwon, 2012.

3. Y.-H. Yun and S.-C. Choi, "Fabrication of SiC Convered Graphite by Chemical Vapor Reaction Method (II) (in Korean)," J. Kor. Ceram. Soc., 36 [1] 21-29 (1999).

4. W.-J. Kim, J. Y. Park, J. -I. Kim, G. W. Hong, and J. Ha, "Deposition of Large Area SiC Thick Films by Low Pressure Chemical Vapor Deposition (LPCVD) Method (in Korean)," J. Kor. Ceram. Soc., 38 [5] 485-91 (2001).

5. G. Chichignoud, M. Ucar-Morais, M. Pons, and E. Blanquet, "Chlorinated Silicon Carbide CVD Revisited for Polycrystalline Bulk Growth,” Surf. Coat. Technol., 201 [22-23] 8888-92 (2007).

6. K. Choi and J.-W. Kim, "Thermodynamic Comparison of Silicon Carbide CVD Process between $\mathrm{CH}_{3} \mathrm{SiCl}_{3}-\mathrm{H}_{2}$ and $\mathrm{C}_{3} \mathrm{H}_{8}-\mathrm{SiCl}_{4}-\mathrm{H}_{2}$ Systems (in Korean)," Kor. J. Met. Mater., 50 [8] 569-73 (2012).

7. J.-W. Kim, J.-W. Seo, K. Choi, and J.-H. Lee, "Application of CFD Simulation to CVD Process (in Korean)," J. Comput. Fluids Eng., 18 [3] 67-71 (2013).

8. K. Choi and J.-W. Kim, "CFD Simulation of Chemical Vapor Deposition of Silicon Carbide in $\mathrm{CH}_{3} \mathrm{SiCl}_{3}-\mathrm{H}_{2}$ System," Curr. Nanosci., In press.

9. Y. Yan and Z. Weigang, "Kinetic and Microstructure of SiC Deposited from $\mathrm{SiCl}_{4}-\mathrm{CH}_{4}-\mathrm{H}_{2}$," Chin. J. Chem. Eng., 17 [3] 419-26 (2009).

10. R. Wang and R. Ma, "Kinetics of Halide Chemical Vapor Deposition of Silicon Carbide Film," J. Crystal Growth, 308 [1] 189-97 (2007).

11. H. Habuka, M. Watanabe, M. Nishida, and T. Sekiguchi, "Polycrystalline Silicon Carbide Film Deposition Using Monomethylsilane and Hydrogen Chloride Gases," Surf. Coat. Technol., 201 [22-23] 8961-65 (2007)

12. J. Nishio, M. Hasegawa, K. Kojima, T. Ohno, Y. Ishida, T. Takahashi, T. Suzuki, T. Tanaka, and K. Arai, "Uniformity of 4H-SiC Epitaxial Layers Grown on 3-in Diameter Substrates," J. Crystal Growth, 258 [1-2] 113-22 (2003).

13. F. M. White, "Fluid Mechanics," $6{ }^{\text {th }}$ Ed., Chap. 4, McGrawHill Korea, Inc., 2008.

14. R. B. Bird and W. E. Stewart, "Transport Phenomena," $2^{\text {nd }}$ Ed., John Wiley \& Sons, New-York, 2001. 